\title{
PERSEPSI PETANI PADI SAWAH TERHADAP KOMPETENSI PENYULUH PERTANIAN LAHAN KERING DI KECAMATAN INSANA UTARA KABUPATEN TIMOR TENGAH UTARA
}

\section{RICE FARMERS' PERCEPTIONS ON THE COMPETENCE OF DRY LAND AGRICULTURAL EXTENDERS IN NORTH INSANA DISTRICT NORTH CENTRAL TIMOR REGENCY}

\author{
Kanisius Kolo $^{1 *}{ }^{*}$ Umbu Joka $^{2}$ Agustinus Nubatonis ${ }^{3}$, Marsianus Falo ${ }^{4}$ \\ ${ }^{1,2,3,4}$ Program Studi Agribisnis Fakultas Pertanian, Universitas Timor, Kefamenanu, Indonesia \\ *Email Penulis korespondensi: kenzokolo2410@gmail.com
}

\begin{abstract}
Abstrak
Presepsi merupakan penilaian seseorang yang berdasarkan hasil pemikiran kita. Sedangkan Kompetensi penyuluh pertanian dapat diukur berdasarkan kinerja serta tugas dan peran penyuluh itu sendiri. Kompetensi merupakan kemampuan tugas-tugas secara efektif, sedangkan makna profesional merujuk tingkat keahlian atau keterampilan yang didasarkan dalam menjalankan tuntutan tugas atau profesinya. Tujuan penelitian ini untuk mengetahui; 1) gambaran umum peyuluh pertanian lapangan dan; 2) untuk mengetahui hubungan antara persepsi petani padi sawah terhadap kompetensi penyuluh pertanian lapangan di Kecamatan Insana Utara Kabupaten Timor Tengah Utara. Penelitian ini dilaksanakan di Kecamatan Insana Utara, Kabupaten Timor Tengah Utara pada bulan januari 2021. Teknik pengambilan sampel dalam penelitian ini menggunakan purposive sampling sehingga diperoleh sampel sebanyak 30 responden. Pelaksanaan kegiatan penyuluhan pertanian di Kecamatan Insana Utara Kabupaten Timor Tenggah Utara yang bertujuan untuk meningkatkan Intesitas penyuluhan, Materi penyuluhan, serta Metode penyuluhan. Hasil penelitian persepsi petani padi sawah terhadap kompetensi penyuluh di Kecamatan Insana Utara cukup baik dengan tingkat berpengaruhya 2,02\%, diikuti materi penyuluh kurang baik/tidak setuju dengan tingkat berpengaruhnya 2,32\%, dan metode penyuluh baik dengan tingkat berpengaruhnya $2,42 \%$. Total rata-rata kompetensi penyuluh pertanian dikelompok tani bernilai 2,25 yang termasuk dalam kategori cukup baik, artinya kelompok tani baik dengan pemberdayaan yang dilakukan dikelompok tani.
\end{abstract}

Kata Kunci : Persepsi, Petani, Kompetensi, Penyuluh, dan Padi Sawah

\begin{abstract}
Perception is a person's judgment based on the results of our thoughts. Meanwhile, the competence of agricultural instructors can be measured based on the performance and duties, and roles of the extension workers themselves. Competence is the ability to perform tasks effectively, while professional meaning refers to the level of expertise or skills based on carrying out the demands of the task or profession. The purpose of this research is to find out; 1) a general description of field agricultural extension workers and; 2) to determine the relationship between the perception of lowland rice farmers on the competence of field agricultural instructors in North Insana District, North Central Timor Regency. This research was conducted in North Insana District, North Central Timor Regency in January 2021. The sampling technique in this study used purposive sampling so that a sample of 30 respondents was obtained. Implementation of agricultural extension activities in North Insana District, North Central Timor Regency which aims to increase the intensity of extension, extension materials, and extension methods. The results of the research on the perception of lowland rice farmers on the competence of the instructor in North Insana Sub-district were quite good with an influence level of $2.02 \%$, followed by the instructor material being not good/disagree with the level of influence $2.32 \%$, and the extension method being good with an effective level of $2.42 \%$. The total average competency of agricultural instructors in the farmer group is 2.25 which is included in the fairly good category, meaning that the farmer group is good with empowerment carried out in the farmer group.
\end{abstract}

Keywords: Perception, Farmers, Competence, Extension, and Paddy Rice

Kolo, K., Joka, U., Nubatonis, A., dan Falo, M. 


\section{PENDAHULUAN}

Sektor pertanian merupakan salah satu sektor penting dalam pembangunan nasional. Peran strategis sektor pertanian berkontribusi sebagai penyedia bahan pangan serta bahan baku industri. Selain menyumbang Pendapatan Domistik Bruto (PDB), penghasil devisa Negara, penyerap tenaga kerja, dan sumber utama pendapatan rumah tangga pedesaan. Pembangunan pertanian untuk mewujudkan kedaulatan pangan Indonesia bangsa yang dapat mengatur dan memenuhi kebutuhan sektor pangan yang berdaulat.

Kompetensi penyuluh pertanian dapat diukur berdasarkan kinerja serta tugas dan peran penyuluh itu sendiri. Kompetensi merupakan kemampuan tugas-tugas secara efektif, sedangkan makna profesional merujuk tingkat keahlian atau keterampilan yang didasarkan dalam menjalankan tuntutan tugas atau profesinya (Imran, 1999). Dengan demikian kompetensi penyuluh adalah derajat kemampuan yang dimiliki penyuluh didalam menjalankan tugas atau tuntutan profesinya secara efektif.

Kabupaten Timor Tengah Utara merupakan salah satu Kabupaten di Provinsi Nusa Tenggara Timur yang memiliki berbagai potensi di bidang pertanian yang mencakup dan memiliki daya dukung peningkatan produksi hasil pertanian melalaui peyuluh pertanian lahan kering. Wilayah lahan kering yang luas di Kabupaten Timor Tengah Utara sangat berpotensi untuk pengembangan tanaman pangan salah satunya adalah tanaman padi. Tanaman Padi merupakan komoditi strategis dalam pembangunan pertanian (Septiadi \& Joka, 2019), sehingga peningkatan kompetensi penyuluh di daerah ini sangat dibutuhkan untuk mengoptimalkan kegiatan usahatani komoditas padi dalam upaya peningkatan kapasitas produksi.

Kabupaten Timor Tengah Utara memiliki salah satu kecamatan yang mayoritas masyarakatnya bermatapencaharian sebagai petani lahan kering yaitu Kecamatan Insana Utara. Kecamatan Insana Utara merupakan salah satu Kecamatan yang mayoritas petaninya adalah petani lahan kering dengan luas areal mencapai 101,37 km2. Masyarakat di Kecamatan Insana Utara mayoritasnya berusahatani padi sawah. Untuk menunjang produksi padi di wilayah tersebut, petani menggunakan irigasi (saluran) dengan binaan dari peyuluh pertanian. Jumlah penyuluh yang membina kelompok tani di Kecamatan Insana Utara berjumlah 3 orang. Umumnya petani di Kecamatan Insana Utara menggunakan sistem tanam biasa (konvensional), agar meningkatkan produksi padi serta memudahkan perawatan dan penyuluh pertanian lapangan memberikan inovasi baru yaitu teknologi sistem tanam.

Bedasarkan penjelasan tersebut maka tujuan dalam penelitian ini untuk mengetahui: 1) gambaran umum peyuluh pertanian lapangan dan; 2) untuk mengetahui hubungan antara persepsi petani padi sawah terhadap kompetensi penyuluh pertanian lapangan di Kecamatan Insana Utara Kabupaten Timor Tengah Utara.

\section{METODE PENELITIAN}

\section{Sumber Data}

Penelitian ini dilakukan dengan menggunakan metode survei, wawancara dan observasi dari sumber yang dijadikan responden dalam suatu penelitian misalnya: petani dan pedagang.

Kolo, K., Joka, U., Nubatonis, A., dan Falo, M. 


\section{Teknik Pengumpulan Data}

Data primer adalah sumber data penelitian yang diperoleh secara langsung dari sumber asli (tidak melalui perantara) sumber penelitian secara khusus dikumpulkan peneliti untuk menjawab pertanyaan penelitian. Data primer dapat berupa opini subyek (orang) secara individu maupun kelompok hasil observasi terhadap suatu benda (fisik), kejadian atau kegitan, dan hasil pengujian (Alsa, 2007). Data sekunder adalah sumber data penelitian yang diperoleh peneliti secara tidak langsung melalui media perantara (diperoleh dari catatan pihak lain) seperti penyuluh pertanian setempat, pemerintah terkait, studi kepustakaan dan referensi lainnya.

\section{Analisis Deskriptif}

Analisis Deskriptif adalah analisis yang menghasilkan output data sampai pada taraf deskriptif, yaitu menganalisis dan menyajikan fakta secara sistematik sehingga dapat lebih mudah dipahami dan disimpulkan (Winartha, 2006).

\section{Skala Likert}

Skala Likert digunakan untuk mengukur persepsi seseorang atausekelompok orang tentang kejadian atau gejala sosial. Dalam penelitian ini menyangkut persepsi/penelitian analisis faktor-faktor yang mempengaruhi presepsi petani terhadap penyuluh pertanian yang ada di kecamatan Insana Utara (Suhardjo 1996).

\section{HASIL DAN PEMBAHASAN}

\section{Gambaran Umum Peyuluh}

Metode pengukuran data menggunakan skala likert dengan penjelasan sebagai berikut:

\section{Intensitas Penyuluhan}

Tabel 1. Distribusi Pengukuran Data Intensitas Penyuluh

\begin{tabular}{llll}
\hline Kategori & Interval Kelas & Frekuensi (orang) & Presentase (\%) \\
\hline Baik & $2,34-3$ & 0 & 0 \\
Cukup Baik & $1,67-2,33$ & 30 & 100 \\
Kurang Baik & $1-1,66$ & 0 & 0 \\
\hline Total & & 30 & 100 \\
\hline Rata-rata & & & $\mathbf{2 , 0 2}$
\end{tabular}

Sumber: Data Primer, diolah(2021)

Berdasarkan tabel 1 di atas dapat dijelaskan bahwa intensitas penyuluh terhadap penyuluh pertanian di Kecamatan Insana Utara dilihat dengan interval kelas 2,34 - 3 sebanyak 0 orang tergolong dalam kategori baik dengan presentase $0 \%$, diikuti dengan interval kelas 1,67 - 2,33 sebanyak 30 orang tergolong dalam kategori cukup baik dengan presentase sebesar $100 \%$, dan interval kelas $1-1,66$ sebanyak 0 orang tergolong dalam kategori kurang baik dengan presentase 0\% dengan skor rata-rata sebesar 2,02 yang tergolong dalam kategori cukup baik. Hal ini menunjukan bahwa penyuluh pertanian di kelompok tani pada tahap intensitas penyuluh sudah baik karena adanya kerja sama antara pengurus dan anggota.

Kolo, K., Joka, U., Nubatonis, A., dan Falo, M. 


\section{Materi Penyuluhan}

Tabel 2. Distribusi Data Materi Penyuluh

\begin{tabular}{llll}
\hline Kategori & Interval Kelas & Frekuensi (orang) & Presentase (\%) \\
\hline Baik & $2,34-3$ & 25 & 83,33 \\
Cukup Baik & $1,67-2,33$ & 2 & 6,66 \\
Kurang baik & $1-1,66$ & 3 & 10 \\
\hline Total & & 30 & 100 \\
\hline Rata-rata & & & $\mathbf{2 , 3 2}$
\end{tabular}

Sumber: Data Primer, diolah (2021)

Tabel 2 di atas dapat dijelaskan bahwa materi penyuluh yang diterapkan oleh penyuluh pertanian di kelompok tani dengan interval kelas 2,34-3 sebanyak 25 orang tergolong kategori baik dengan presentase $83,33 \%$, diikuti dengan interval kelas 1,672,33 sebanyak 2 orang dengan kategori cukup baik dengan presentase $6,66 \%$, dan materi penyuluh dengan interval kelas 1-1,66 sebanyak 3, orang tergolong dalam kategori kurang baik dengan presentase $10 \%$ dengan rata-rata sebesar 2,32 yang tergolong dalam kategori cukup baik. Hal ini menunjukan bahwa materi penyuluh pertanian yang di terapkan pada kelompok tani sudah baik karena adanya kerja sama antara pengurus dan anggota. Lebih lanjut menurut Slamet (2003b), kepuasan petani dari penyuluhan tidak hanya kalau materi penyuluhan itu sesuai dengan apa yang dibutuhkan, tetapi cara penyajian juga akan berpengaruh pada kepuasannya itu. Oleh karena itu, materi penyuluhan yang tepat haruslah disajikan dengan sikap kepelayanan sepenuh hati. Penyuluh pertanian harus selalu lebih baik dan lebih mampu dari sebelumnya.

\section{Metode Penyuluhan}

Tabel 3. Distribusi Data Metode Penyuluh

\begin{tabular}{llll}
\hline Kategori & Interval Kelas & frekuensi (orang) & presentase (\%) \\
\hline Baik & $2,34-3$ & 27 & 90 \\
Cukup Baik & $1,67-2,33$ & 3 & 10 \\
Kurang Baik & $1-1,66$ & 0 & 0 \\
\hline Total & & 30 & 100 \\
\hline Rata-rata & & & 2,42 \\
\hline
\end{tabular}

Sumber: Data Primer,diolah(2021)

Pada tabel 3 dapat dijelaskan bahwa metode penyuluh pada kelompok tani dengan interval kelas 2,34-3 sebanyak 27 orang tergolong dalam kategori baik dengan presentase $90 \%$, interval kelas 1,67-2,33 sebanyak 3 orang, tergolong dalam kategori cukup baik dengan presentase 10\%, dan diikuti interval kelas 1-1,66 sebanyak 0 orang, tergolong dalam kategori kurang baik dengan presentase $0 \%$ dengan skor rata-rata sebesar 2,42 yang tergolong dalam kategori baik. Metode perorangan sendiri menurut Kartasaputra (Setiana, 2005) memang sangat efektif digunakan dalam penyuluhan karena sasaran dapat secara langsung memecahkan masalahnya dengan bimbingan khusus dari penyuluh. Namun jika dilihat dari segi jumlah sasaran yang ingin dicapai, metode ini kurang efektif karena terbatasnya jangkauan penyuluh untuk mengunjungi dan membimbing sasaran secara individu. . Hal ini menunjukan bahwa metode penyuluh pertanian pada kelompok tani sudah baik. Pertemuan kelompok yang rutin dilakukan dan penyuluh swadaya juga turut membuat petani di desa ini lebih individualistik dalam berusahatani. 
Tabel 4. Rata-rata keseluruhan untuk kompetensi penyuluh pertanian

\begin{tabular}{lll}
\hline Kompetensi Peyuluh & Rata-rata & Kategori \\
\hline Intesitas Penyuluhan & 2,02 & Cukup Baik \\
Materi Penyuluhan & 2,32 & Cukup Baik \\
Metode Penyuluhan & 2,42 & Baik \\
\hline Total & 6,76 & \\
\hline Rata-rata & 2,25 &
\end{tabular}

Sumber: Sumber data diolah 2021

Data pada tabel 4 dapat dijelaskan bahwa rata-rata penyuluh pertanian pada intensitas bernilai 2,02 dengan kategori cukup baik, materi penyuluh dengan bernilai 2,32dengan kategori cukup baik, dan diikuti metode penyuluh dengan bernilai 2,42 dengan kategori baik. Berdasarkan hasil penelitian, total rata-rata kompetensi penyuluh pertanian dikelompok tani bernilai 2,25 yang termasuk dalam kategori cukup baik, artinya kelompok tani sangat setuju dengan pemberdayaan yang dilakukan dikelompok tani.

\section{Persepsi Petani Terhadap Kompetensi Penyuluh}

Tabel 5. Rata-rata keseluruhan untuk Persepsi Petani Terhadap Kompetensi Penyuluh

\begin{tabular}{lcl}
\hline Persepsi petani & Rata-rata & Kategori \\
\hline Kepribadian & 1,96 & Cukup Baik \\
Andragogik & 1,83 & Cukup Baik \\
Professional & 1,54 & Kurang Baik \\
Sosial & 2,1 & Cukup Baik \\
\hline Total & $\mathbf{7 , 5 7}$ & \\
\hline
\end{tabular}

Sumber: Sumber data diolah 2021

Data pada tabel 5 dapat dijelaskan bahwa rata-rata persepsi petani pada kepribadian bernilai 1,96 dengan kategori cukup baik, Andragogik dengan bernilai 1,83 dengan kategori cukup baik, dan diikuti professional dengan bernilai 1,54 dengan kategori kurang baik diikuti sosial bernilai 2,1 dengan kategori baik. Berdasarkan hasil penelitian, total rata-rata persepsi petani dikelompok tani bernilai 1,89 yang termasuk dalam kategori cukup baik, artinya kelompok tani sangat setuju dengan pemberdayaan yang dilakukan dikelompok tani. Tingkat kompetensi andragogik penyuluh alumni UT relatif sedang (skor 0,59). Namun demikian, tingkat pengetahuan dan tindakannya relatif rendah, sedangkan tingkat keyakinannya relatif tinggi. Hal ini menunjukkan bahwa walaupun penyuluh alumni UT mempunyai pemahaman dan tindakan andragogik yang rendah, namun memiliki sikap yang positif tentang pembelajaran orang dewasa. Tingkat kompetensi sosial penyuluh alumni UT relatif sedang (skor $0,64)$, yang terlihat dari tindakannya. Namun tingkat pengetahuannya relatif rendah sedangkan sikap mentalnya relatif tinggi. Hal ini menunjukkan bahwa keterampilan sosial penyuluh alumni UT sudah cukup baik. Walaupun penyuluh alumni UT mempunyai pemahaman sosial yang relatif rendah, namun memiliki keyakinan sosial yang tinggi, khususnya yang berkaitan dengan berkomunikasi dan bekerjasama.

Hasil penelitian dari Anwas (2011), "Kompetensi Penyuluh Pertanian dalam Memberdayakan Petani" menjelaskan bahwa tingkat kompetensi penyuluh dalam dimensi pemahaman potensi wilayah di daerah pertanian sayuran lebih tinggi dibandingkan dengan penyuluh yang bertugas di daerah pertanian padi. Pemahaman terhadap potensi wilayah ini sangat penting dalam melaksanakan penyuluhan agar sesuai dengan potensi wilayah dan kebutuhan klien. Hasil penelitian Murfiani dan Amri Jahi (2006), menyimpulkan bahwa tiga bidang kompetensi yang perlu dikuasai oleh

Kolo, K., Joka, U., Nubatonis, A., dan Falo, M. 
penyuluh dalam mengembangkan modal agribisnis kecil ialah (1) merencanakan program penyuluhan pertanian, (2) melaksanakan program penyuluhan pertanian, dan (3) mengembangkan swakarsa dan swadaya petani. Hasil penelitian ini searah dengan hasil penelitian dari Marliati et al., (2008), tentang "Faktor-Faktor Penentu Peningkatan Kinerja Penyuluh Pertanian dalam Membeberdayakan Petani" menyimpulkan bahwa kinerja penyuluh pertanian secara langsung dapat dipengaruhi oleh kompetensi penyuluh dalam melakukan hubungan interpersonal terutama pada waktu penyusunan program penyuluhan dan implementasi program penyuluhan.

\section{Hubungan penyluh terhadap persepsi petani}

Tabel 6. Hubungan penyluh terhadap persepsi petani

\begin{tabular}{|c|c|c|c|c|c|}
\hline \multicolumn{6}{|l|}{ Correlations } \\
\hline & & Kompetensi & Intensitas & Materi & Metode \\
\hline & & Penyuluh & Penyuluh & Penyuluh & Penyuluh \\
\hline \multirow{4}{*}{$\begin{array}{l}\text { Pearson } \\
\text { Correlation }\end{array}$} & Kompetensi Penyuluh & 1.000 & .189 & .189 & .189 \\
\hline & Intensitas Penyuluh & .189 & 1.000 & 1.000 & 1.000 \\
\hline & Materi Penyuluh & .189 & 1.000 & 1.000 & 1.000 \\
\hline & Metode Penyuluh & .189 & 1.000 & 1.000 & 1.000 \\
\hline \multirow[t]{4}{*}{ Sig. (1-tailed) } & Kompetensi Penyuluh & . & .159 & .159 & .159 \\
\hline & Intensitas Penyuluh & .159 & . & .000 & .000 \\
\hline & Materi Penyuluh & .159 & .000 & . & .000 \\
\hline & Metode Penyuluh & .159 & .000 & .000 & . \\
\hline \multirow[t]{4}{*}{$\mathrm{N}$} & Kompetensi Penyuluh & 30 & 30 & 30 & 30 \\
\hline & Intensitas Penyuluh & 30 & 30 & 30 & 30 \\
\hline & Materi Penyuluh & 30 & 30 & 30 & 30 \\
\hline & Metode Penyuluh & 30 & 30 & 30 & 30 \\
\hline
\end{tabular}

Sumber: Data primer, diolah (2021)

* Analisis output spss:

- Kompetensi penyuluh memiliki hubungan yang signifikan terhadap variabel persepsi petani, pada taraf 5\%.Berdasarkan hasil analisis diatas dapat diketahui bahwa nilai sig. (1-tailed) sebesar 0.159>0.05 maka dapat disimpulkan bahwa variabel persepsi petani memiliki hubungan yang signifikan.

- Nilai correlations coefficient bernilai positif sebesar 0.159 maka dapat disimpulkan bahwa variabel kompetensi penyuluh terhadap persepsi petani memiliki hubungan. Secara teori hasil penelitian ini searah dengan pendapat dari Slamet (2003), bahwa program penyuluhan pembangunan yang efektif dan efisien dapat dikembangkan oleh tenaga-tenaga profesional di bidang penyuluhan pembangunan yang program penyuluhannya diwadahi oleh sistem kelembagaan penyuluhan. Secara teori hasil penelitian ini sejalan dengan pendapat dari Bandura (1977). Hasil penelitian ini searah dengan hasil penelitian dari Marliati et al., (2008), tentang "Faktor-Faktor Penentu Peningkatan Kinerja Penyuluh Pertanian dalam Membeberdayakan Petani” menyimpulkan bahwa kinerja penyuluh pertanian secara langsung dapat dipengaruhi oleh kompetensi penyuluh dalam melakukan hubungan interpersonal terutama pada waktu penyusunan program penyuluhan dan implementasi program penyuluhan. Hasil penelitian Husodo (2008) tentang "Membangun Sistem Keprofesian Penyuluh

Kolo, K., Joka, U., Nubatonis, A., dan Falo, M. 
Pertanian" menjelaskan bahwa profesi penyuluh merupakan bagian dari kemampuan penyuluh membangun aksi sosial dengan masyarakat yang terwujud melalui pengembangan kompetensi diri dan motivas ingin berprestasi.

\section{KESIMPULAN DAN SARAN}

Pelaksanaan kegiatan penyuluhan pertanian di Kecamatan Insana Utara Kabupaten Timor Tenggah Utara yang bertujuan untuk meningkatkanIntesitaspenyuluhan, Materi penyuluhan, serta Metode penyuluhan. Hasil penelitian menunjukan bahwa persepsi penyuluh pertanian terhadap kompetensi penyuluh di Kecamatan Insana Utara sangat baik dengan tingkat berpengaruhya 2,02\%, diikuti materi penyuluh kurang baik/tidak setuju dengan tingat berpengaruhnya $2,32 \%$, dan metode penyuluh sangat baik/setuju dengan tingkat berpengaruhnya $2,42 \%$.

\section{DAFTAR PUSTAKA}

Alsa, Asmadi. 2007. Pendekatan kuantitatif \& Kualitatif serta Kombinasinya dalam Penelitian Psikologi. Yogyakarta: Pustaka Pelajar

Anwas, OM. 2011. Kompetensi Penyuluh Pertanian dalam Memberdayakan Petani. Jurnal Matematika, Sains dan Teknologi. Vol. 12. No. 1. Maret 2011. Hal: 46 55.

Arikunto, S. 2002. Metodologi Penelitian Suatu Pendekatan Proposal. Jakarta: PT. Rineka Cipta.

Bandura A. 1977. Social Learning Theory. Englewood Cliffs, New Jersey: PrenticeHall, Inc

Husodo, S. (2008). Membangun Sistem Keprofesian Penyuluh Pertanian. Jurnal Ilmuilmu Pertanian. Vol 4, No. 1, Juli 2008. Hal: 38-46

Imran. 1999. Modul Kesehatan Remaja Melaluiproses Pendidikan Pendampingan Berkelanjutan.

Marliati, M., Sumardjo, S., Asngari, P. S., Tjitropranoto, P., \& Saefuddin, A. (2008). Faktor-Faktor Penentu peningkatan kinerja penyuluh pertanian dalam memberdayakan petani (Kasus di Kabupaten Kampar Provinsi Riau). Jurnal Penyuluhan, 4(2).

Murfiani, F., \& Jahi, A. (2006). The Extension Workers'competency In Developing Small Agribusiness Capital in The District of Bogor, West Java. Jurnal Penyuluhan, 2(4).

Septiadi, D., \& Joka, U. (2019). Analisis Respon dan Faktor-Faktor yang Mempengaruhi Permintaan Beras Indonesia. AGRIMOR, 4(3), 42-44.

Setiana, L. (2005). Pengertian Dasar Penyuluhan Pertanian. Jakarta (ID): Gramedia.

Slamet M. (2003). Pemberdayaan Masyarakat. Dalam: Membentuk Pola Perilaku Manusia. Bogor: IPB Press.

Soekartawi. (1988). Prinsip Dasar Komunikasi Pertanian. Jakarta: Penerbit Universitas Indonesia (UI-Press).

Sugiyono. (2003). Metode Penelitian. Bandung: Alfabeta.

Suhardjo. (1996). Berbagai Cara Pendidikan Gizi. Bumi Aksara. Jakarta.

Winartha, Made. 2006. Metodologi Penelitian Sosial Ekonomi. Yogyakarta Andi Ofsset.

Kolo, K., Joka, U., Nubatonis, A., dan Falo, M. 